\title{
Analysis of Mechanical Parameters and Creep Characteristics of Surrounding Rock in Fully Weathered Sandstone Tunnel
}

\author{
Kaicheng $\mathrm{Hua}^{1}$, hongyan $\mathrm{Guo}^{2 *}, \mathrm{Ke} \mathrm{Li}^{2}$ and Xiang Yang $\mathrm{Cui}^{3}$ \\ ${ }^{1}$ Guangdong Road and Bridge Construction Development Co., Ltd., Guangzhou, 510000, China \\ ${ }^{2}$ China Merchants Chongqing Communications Technology Research \& Design Institute Co., Ltd, Chongqing,400000, China \\ ${ }^{3}$ Chongqing Jiaotong University, Chongqing 400067, China
}

\begin{abstract}
Based on the geological conditions of the fully weathered sandstone stratum in the expressway of the mountainous area, the Huizhou-Qingyuan section of the Yuzhan Expressway is used to analyze the mechanical parameters and creep characteristics of the surrounding rock of the tunnel through the indoor model test. It is concluded that: 1) The uniaxial compression deformation test measured the structural parameters of the fully weathered sandstone stratum structure, and obtained that the elastic modulus and internal friction angle $\phi$ of the fully weathered sandstone was $14.20^{\circ}$, and the cohesion c was $0.343 \mathrm{Mpa}$. 2) The failure mode of fully weathered sandstone specimens was obtained by triaxial creep test. The creep curves of different weathered loads were analyzed and the Xiyuan rheological model was established. 3) The creep data was analyzed by MATLAB software, and the surrounding rock parameters under different surrounding rock were obtained.
\end{abstract}

\section{Introduction}

With the number of highways connecting cities has been increasing, and the engineering problems and difficulties is also increasing exponentially. The fully weathered sandstone clay appeared in the Huiqing-Qingyuan section of the Yuzhan Expressway has certain expansibility and disintegration. After the water encounter, the surrounding rock has large deformation and rapid deformation rate. Especially in Guangzhou, the rainwater is rich, which causes a lot of difficulties construction. Therefore, the analysis of the mechanical and creep properties of the surrounding rock of the fully weathered sandstone tunnel is of great significance for selecting appropriate excavation methods, supporting parameters and selecting support timing and reinforcement measures [1-3].

Zhang Haiyang et al. simulated the creep process during excavation of Dazhanggou inclined shaft test tunnel of Muzhailing Tunnel under the condition of high crustal stress soft rock by numerical simulation. The Creep Mechanics Parameters of the geological conditions of the carbonaceous slate were obtained by inversion of the field monitoring data through BP neural network [4]. Liu Mengbo et al. combined with the experimental data of soft clay in Shanghai area, using the creep model coupled with the time hardening rule and Druker-Prager yield criterion, using numerical simulation method to analyze the variation of soft soil creep characteristics and force with time [5].

In this paper, the mechanical parameters of the fully weathered sandstone stratum are measured by laboratory tests. The creep curves of the specimen under confining pressure are obtained according to the principle of "Chen's loading". The Xiyuan rheological model is established and the creep data is analyzed by MATLAB software. After analysis, the parameters of surrounding rock under different surrounding rock are obtained [6].

\section{Project Profile}

Through on-site observation and analysis, the Taihedong tunnel has a high content of fully weathered sandstone clay minerals, generally 10 to $30 \%$, and its clay minerals will exhibit certain disintegration and swelling properties, and the water-like properties of the rocks deteriorate seriously. This is also the essential reason for the large deformation of the surrounding rock during the rainy season of the tunnel. The exit section of the Taihedong tunnel reveals that the surrounding rock is fully weathered sandstone.

\section{Surrounding rock mechanics parameters}

\section{1 laboratory apparatus}

TAW-200 multi-function rock triaxial test system (Fig. $1)$, the main parameters of the instrument are as follows: test piece size: $\Phi 50 \times 100 \mathrm{~mm}$; maximum axial force: $1000 \mathrm{kN}$; maximum ambient pressure: $60 \mathrm{MPa}$; maximum pore pressure: $60 \mathrm{MPa}$; Heating temperature: $-30-80^{\circ} \mathrm{C}$;

\footnotetext{
*Corresponding author's e-mail: guohongyan@cmhk.com
} 
axial deformation: $0 \sim 20 \mathrm{~mm}$; radial deformation: $0 \sim 5$ mm; axial loading speed: $0.01 \sim 1$.

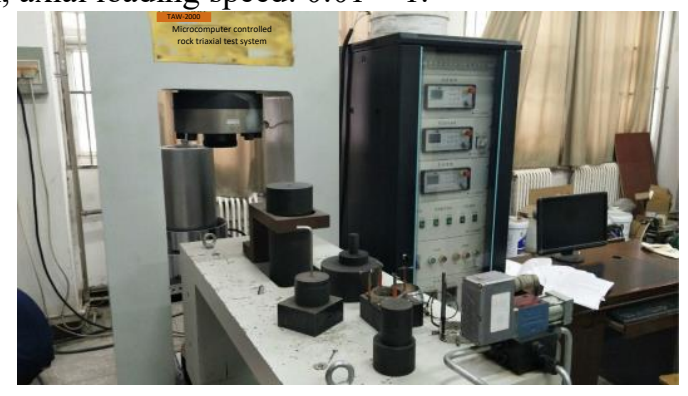

Fig. 1 TAW-200 Multifunctional Rock Triaxial Test System

\subsection{Experimental program}

The uniaxial compression deformation test can measure the elastic modulus E and Poisson's ratio $\mu$ of the fully weathered sandstone remolded soil. The size of the uniaxial compression deformation test specimen of the fully weathered sandstone remolded soil is the diameter $\Phi=50 \mathrm{~mm}$, the height $\mathrm{H}=100 \mathrm{~mm}$. The accuracy of the preparation of the test piece shall not exceed $0.3 \mathrm{~mm}$ in diameter over the entire height of the test piece. The non-parallelism of the two end faces does not exceed $0.05 \mathrm{~mm}$ at the maximum. The end face shall be perpendicular to the axis of the test piece and the maximum deviation shall not exceed $0.25^{\circ}$.

In order to measure the elastic modulus $\mathrm{E}$ and Poisson's ratio $\mu$ of the fully weathered sandstone remolded soil, the loading speed was set to $0.01 \mathrm{~mm} / \mathrm{min}$, and the confining pressure was $0 \mathrm{MPa}$, a total of $1 * 3$ test pieces were prepared.

In order to measure the cohesion $\mathrm{c}$ and the internal friction angle $\varphi$ of the fully weathered sandstone remolded soil, confining pressure is $0.4 \mathrm{MPa}$ and 0.6 $\mathrm{MPa}, 0.8 \mathrm{MPa}, 1.0 \mathrm{MPa}$ and $1.2 \mathrm{MPa}$. a total of $5^{*} 3$ test pieces were prepared.

In order to obtain the rheological parameters of the fully weathered sandstone remolded soil. The axial load of the test was carried out in a stepwise incremental loading mode, which was divided into five grades $(0.6$
$\mathrm{MPa}, 0.8 \mathrm{MPa}, 1.0 \mathrm{MPa}, 1.2 \mathrm{MPa}, 1.4 \mathrm{MPa}, 1.6 \mathrm{MPa}) . \mathrm{A}$ total of $1 * 3$ test pieces were prepared for the test.

\subsection{Experimental result}

The peak value of the axial stress and axial strain curves is taken as the uniaxial compressive strength, and the uniaxial compression test results of the fully weathered sandstone remolded soil are shown in Table 1.

Table 1 Uniaxial compression test results of fully weathered sandstone remolded soil

\begin{tabular}{cccc}
\hline & $\begin{array}{c}\text { Axial stress } \\
\text { peak } S_{c} \\
\mathrm{MPa}\end{array}$ & $\begin{array}{c}\text { Secant } \\
\text { modulus } \\
\mathrm{MPa}\end{array}$ & $\begin{array}{c}\text { Poisson's } \\
\text { ratio }\end{array}$ \\
\hline Test piece 1 & 1.0 & 23.81 & 0.32 \\
\hline Test piece 1 & 0.8 & 16.33 & 0.38 \\
\hline Test piece 1 & 0.5 & 13.89 & 0.34 \\
\hline $\begin{array}{c}\text { average } \\
\text { value }\end{array}$ & 0.77 & 18.01 & 0.35 \\
\hline
\end{tabular}

Taking the peak value of the relationship curve between the axial stress and the axial strain as the triaxial compressive strength After averaging the peak intensities measured by the triaxial compression test under five confining pressures, the surrounding stress is plotted on the abscissa according to the Mohr Coulomb strength criterion. The axial stress is the ordinate and the relationship curve when the rock sample is destroyed. By fitting the test data, the slope of the fitted straight line is $\mathrm{k}$, and the intercept with the ordinate is a, and the obtained intensity coefficient $\mathrm{k}$ is 1.65 , a is 0.88 , and the internal friction angle $\varphi$ is $14.20^{\circ}$, and the cohesion is obtained. The force $\mathrm{c}$ is $0.343 \mathrm{MPa}$.

\section{Creep characteristics}

\subsection{Triaxial creep test results}

The fully weathered sandstone remolded soil typical of the triaxial creep test is shown in Fig. 2.

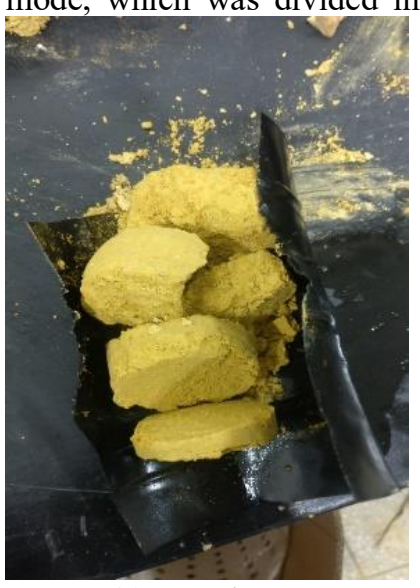

(a) Test piece 1

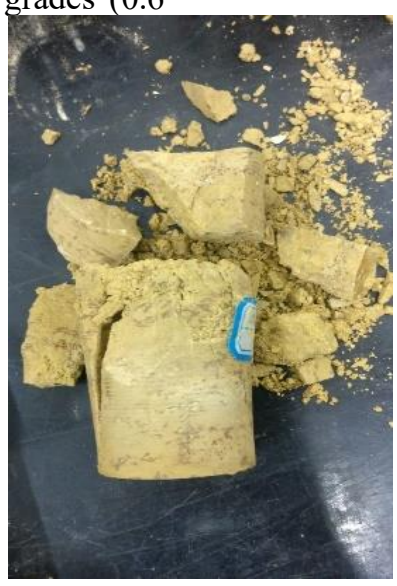

(b) Test piece 2

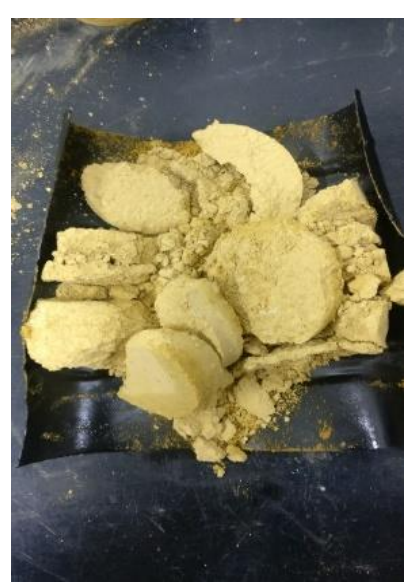

(c) Test piece 3

Fig.2 Fully weathered sandstone remolded soil specimen after triaxial compression creep damage 


\subsection{Analysis of test results}

At the time of loading, it should be noted that the time interval of the step-by-step loading should be equal, and the lower-level loading must be performed after the deformation of the pre-stage load has entered the steady-state creep. According to the principle of "Chen's loading" method, the creep curve under different loads can be obtained. Due to the low strength of the original rock specimens and the looser particles, the test results of the specimens are more discrete. The number of grades of test piece 1 and test piece 2 is small, and the test result of test piece 3 is selected for analysis, as shown in Fig. 3.

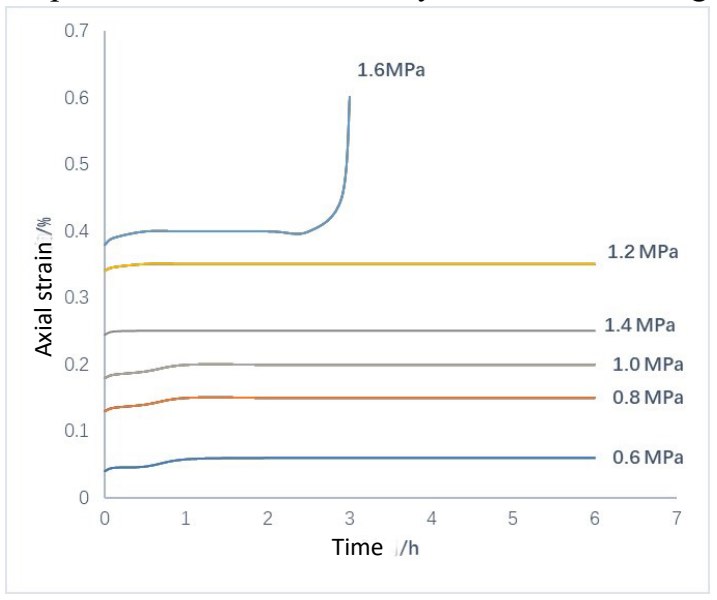

Fig. 3 Creep curve of specimen 3 under different loads

\subsection{Analysis of creep characteristics}

According to the characteristics of the creep curve obtained by the experiment, the comparative analysis shows that the Nishihara rheological model is more suitable for simulating its rheological characteristics. Under the triaxial stress, the nonlinear viscoelastic-plastic creep constitutive equation of rock is (Xiyuan model):

$$
\begin{aligned}
& \varepsilon= \frac{\sigma_{1}+2 \sigma_{3}}{9 K}+\frac{\sigma_{1}-\sigma_{3}}{3 G_{0}}+\frac{\sigma_{1}-\sigma_{3}}{3 G_{1}}\left(1-\mathrm{e}^{-\frac{G_{1}}{\eta_{1}}}\right), \sigma_{1} \leq \sigma_{s} \\
& \varepsilon= \frac{\sigma_{1}+2 \sigma_{3}}{9 K}+\frac{\sigma_{1}-\sigma_{3}}{3 G_{0}}+\frac{\sigma_{1}-\sigma_{3}}{3 G_{1}}\left(1-\mathrm{e}^{-\frac{G_{1}}{\eta_{1}} t}\right)+\frac{\sigma_{1}-\sigma_{s}}{2 \eta_{2}} t, \sigma_{1}>\sigma_{s} \\
& K \text { - Bulk modulus } \\
& G_{0} \text { - Instantaneous shear modulus } \\
& G_{1} \text { - Shear modulus } \\
& h_{1}, h_{2} \text { - Viscosity coefficient }
\end{aligned}
$$

The parameters in the above formula are identified by MATLAB. The surrounding rock parameters under different surrounding rock are optimized as shown in Table 2.

Table 2. Triaxial compression creep model parameter identification results

\begin{tabular}{ccccccc}
\hline$\sigma / \mathrm{MPa}$ & $K / \mathrm{MPa}$ & $G_{0} / \mathrm{MPa}$ & $G_{1} / \mathrm{MPa}$ & $h_{1} / \mathrm{MPa} \cdot \mathrm{h}$ & $h_{2} / \mathrm{MPa} \cdot \mathrm{h}$ & $\mathrm{R}^{2}$ \\
\hline $0.6 \mathrm{MPa}$ & 10.67 & 12.93 & 527.60 & 487.95 & - & 0.98851 \\
\hline $0.8 \mathrm{MPa}$ & 7.91 & 17.13 & 356.91 & 286.62 & - & 0.993767 \\
\hline $1.0 \mathrm{MPa}$ & 7.28 & 19.08 & 260.03 & 262.31 & - & 0.982397 \\
\hline $1.2 \mathrm{MPa}$ & 6.88 & 20.74 & 204.31 & 220.12 & - & 0.983596 \\
\hline $1.4 \mathrm{MPa}$ & 6.61 & 22.03 & 170.65 & 190.25 & - & 0.994435 \\
\hline $1.6 \mathrm{MPa}$ & 6.81 & 23.72 & 179.34 & 25.32 & 18.65 & 0.995565 \\
\hline
\end{tabular}

\section{Conclusion}

In this chapter, through the indoor test and numerical limit analysis of surrounding rock mechanical properties, the surrounding rock stability, instability failure mode and monitoring and early warning standards of the fully weathered sandstone section of Taihe tunnel are studied, and the following conclusions are obtained.

(1) The mechanical parameters of the strongly weathered argillaceous sandstone were obtained through laboratory tests. The internal friction angle $\varphi$ was $14.20^{\circ}$ and the cohesion c was $0.343 \mathrm{Mpa}$.

(2) Through the triaxial creep test, different confining pressures are applied to the fully weathered sandstone. According to the principle of the Chen loading method, the creep curves under different loads can be obtained, and the suitable conditions for the surrounding rock are obtained. Rheological model, and the creep model parameters are obtained through MATLAB software analysis.

\section{Acknowledgments}

National Key Research and Development Plan of China (2017YFC08060010, 2017YFC08060003), This work is financially supported by Security Science and Technology Innovation Project for Social Undertakings and People's Livelihood Guarantee in Chongqing, China (cstc2017shmsA30010), Project of the National Natural Science Foundation of China (41601574). 


\section{Reference}

1. Wen L., Cheng Q.G., Cheng Q., Guo X.F. (2019) Research on creep test of anchor in-situ scale model of suspension bridge[J/OL]. Journal of Southwest Jiaotong University: 1-9

2. Zhu J.L., Chen Q.N. (2019) Sensitivity Analysis and Intelligent Inversion of Mechanical Parameters of Surrounding Rock of Baishui Tunnel[J]. Journal of Hunan University of Arts and Science: Natural Science Edition, 31(02): 85-89.

3. Zhang F.R., Jiang Y.N., Jiang Z.B., Zhang G.T. (2019) Experimental study on rock damage under chemical corrosion-freezing-thawing[J/OL]. Rock and Soil Mechanics, (10):1-11.

4. Zhang H.Y., Xu W.J., Wang Y.G. (2018) Inversion and creep study of mechanical parameters of anisotropic soft rock in tunnels[J]. Chinese Journal of Underground Space and Engineering, 14(S1):159-169.

5. Liu M.B., Liao S.M., Zhu M.Y., Yang J.L., Men Y.Q. (2017) Analysis of the Influence of Soft Soil Creep on Tunnel Structure Load and Deformation[J]. Modern Tunnel Technology, 54(04): 107-114+122.

6. Liu F., Hu X.Y., Gao F. (2019) Study on the mechanical characteristics of TBM tunnel segment lining considering creep properties of surrounding rock $[\mathrm{J}]$. Railway standard design, 63 (05): 124-128+173. 